\title{
Studi Pelacakan Alumni Keguruan STKIP Andi Matappa
}

\author{
Sitti Busyrah Muchsin ${ }^{1}$, Hasbahuddin ${ }^{2}$ \\ ${ }^{1}$ Program Studi Pendidikan Matematika STKIP Andi Matappa \\ ${ }^{2}$ Program Studi Bimbingan dan Konseling STKIP Andi Matappa \\ Email: :sittibusyrah@yahoo.co.id
}

\begin{abstract}
Abstrak. Penelitian ini dilakukan dengan tujuan: 1) Menggali informasi dari alumni mengenai perkembangan kompetensi yang dibutuhkan pasar kerja untuk bahan perbaikan kurikulum; 2) Melakukan penelusuran tempat kerja, bidang kerja, waktu tunggu memperoleh pekerjaan, gaji pertama, pekerjaan sekarang, dan informasi lainnya dari alumni STKIP Andi Matappa. Adapun disain Tracer Study ini menggunakan survey sensal yakni populasi yang dijadikan target studi adalah seluruh populasi dari kohort lulusan tahun 2015 dengan jumlah lulusan 213 orang dimana 136 dari prodi Bimbingan dan Konseling dan 95 dari prodi Pendidikan Matematika. Adapun metode pengumpulan data yang akan digunakan adalah metode online dengan menggunakan perangkat lunak QTAFI (Question Table and Figure). Instrumen yang digunakan adalah kuesioner standar Indotrace yang diadaptasi sepenuhnya yang mencakup pertanyaan yang tercantum pada kuesioner inti Tracer Study Online Kemristekdikti. Hasil penelitian menunjukkan bahwa alumni membutuhkan maksimal 5 bulan untuk mendapatkan pekerjaan pertama setelah lulus dan tiga cara tertinggi memperolehnya melalui relasi, internet dan iklan kerja. Sebanyak $71 \%$ alumni STKIP Andi Matappa bekerja di instansi pemerintah. Mayoritas lulusan telah bekerja sesuai bidang ilmu yang ditempuh selama masa studi, namun perlu penguatan dalam beberapa hal khususnya dalam kemampuan bahasa asing dan komputer agar lulusan dapat bekerja sesuai dengan perkembangan Ilmu Pengetahuan dan Teknologi.
\end{abstract}

Kata Kunci: Tracer Study; Alumni, Kerja.

Abstract. This research was conducted with the aim of: 1) Digging information from alumni about the development of competencies needed by the labor market for curriculum improvement materials; 2) Conduct workplace tracking, work area, waiting time to get a job, first salary, current job, and other information from alumni of Andi Matappa. The tracer study design uses a sensory survey that is the target population of the study is 2015 graduated cohort with a total of 213 graduates, of whom 136 are from Guidance and Counseling and 95 from Mathematics Education. The data collection method used is the online method using QTAFI software (Question Table and Figure). The instrument used is a fully adapted Indotrace standard questionnaire that includes questions listed in the core questionnaire of Tracer Study Online Kemristekdikti. The results showed that alumni need a maximum of 5 months to get the first job after graduation and the three highest ways to get it through relationships, internet and advertising work. Amount $71 \%$ of alumni STKIP Andi Matappa work in government agencies. The majority of graduates have worked according to the field of science pursued during the study period, but need strengthening in some respects especially in the ability of foreign languages and computers so that graduates can work in accordance with the development of Science and Technology.

Keywords: Tracer Study; Alumni; Work. 


\section{PENDAHULUAN}

Guna mencapai lulusan dengan kualifikasi yang sesuai dengan kebutuhan pasar dan persaingan global pada era Masyarakat Ekonomi Asean (MEA) saat ini, diperlukan kegiatan tracer study. Kegiatan tersebut mempunyai nilai yang sangat strategis bagi pengembangan perguruan tinggi, karena dengan informasi yang diperoleh mampu menjadi bahan evaluasi agar proses belajar mengajar ditingkatkan sehingga lulusan dapat terserap di pasar kerja dengan maksimal. Hal ini senada dengan yang diungkapakan Asmawi (2005), Bakhtiar,MI. (2014, 2017) bahwa kegiatan Tracer Study sangat berdampak pada pengembangan pendidikan di kampus karena dengan melalui program tersebut maka perguruan tinggi akan mempersiapkan lulusan sesuai dengan kompetensi yang diperlukan di dunia kerja sehingga tidak tertutup kemungkinan akan dilakukan berbagai perubahan dalam proses pendidikan terutama dalam perubahan sistem dan kurikulum pembelajaran di perguruan tinggi.

Kenyataannya sejak berdiri tahun 2000

STKIP Andi Matappa sampai saat ini data dan inventarisasi mengenai penyerapan, proses, dan posisi lulusan pada dunia kerja masih sangat minim. Sehingga, penyelenggaraan kegiatan Tracer Study dianggap sangat urgen karena dapat memberikan outcome bagi penyelenggaraan pendidikan di STKIP Andi Matappa. Tracer Study dapat memberikan masukan kepada STKIP Andi Matappa mengenai penyerapan, proses, dan posisi lulusannya dalam dunia kerja. Data tersebut sangat berguna bagi perubahan dan perkembangan sistem pendidikan di STKIP Andi Matappa. Masukkan tersebut menjadi rujukan dalam meramu dan menyusun kurikulum pendidikan STKIP Andi Matappa dalam mempersiapkan lulusan yang dibutuhkan dunia kerja baik secara nasional maupun secara global.

Olehnya itu tujuan Tracer Study ini adalah: 1) Menggali informasi dari alumni mengenai perkembangan kompetensi yang dibutuhkan pasar kerja untuk bahan perbaikan kurikulum; 2) Melakukan penelusuran tempat kerja, bidang kerja, waktu tunggu memperoleh pekerjaan, gaji pertama, pekerjaan sekarang, dan informasi lainnya dari alumni STKIP Andi Matappa.

\section{METODE}

Disain Tracer Study ini menggunakan survey sensal yakni populasi yang dijadikan target studi adalah seluruh populasi dari kohort lulusan tahun 2015. Jumlah lulusan pada tahun 2015 adalah 213 orang dimana 136 dari prodi Bimbingan dan Konseling dan 95 dari prodi Pendidikan Matematika. Kegiatan ini dilaksanakan selama 5 bulan yakni April - November 2017.

Adapun metode pengumpulan data yang akan digunakan adalah metode online dengan menggunakan perangkat lunak QTAFI (Question Table and Figure). Kemudian, instrumen yang digunakan adalah kuesioner standar Indotrace yang diadaptasi sepenuhnya yang mencakup pertanyaan yang tercantum pada kuesioner inti Tracer Study Online Kemristekdikti.

Secara garis besar kegiatan yang akan dilakukan oleh lembaga Career Development Center pada pelaksanaan Tracer Study terdiri dari tiga fase yang diuraikan sebagai berikut:

1. Fase 1 Persiapan

a. Pengembangan kuesioner (diadaptasi dari kuesioner Indotrace)

b. Persiapan database alumni kohort 2015

c. Persiapan peralatan

2. Fase 2 Pelaksanaan (pengumpulan data)

a. Email blast ke target responden

b. Cek responden yang belum merespons

c. Menerapkan sistem reminder sebanyak 3 kali

3. Fase 3 Analisis data dan pelaporan
a. Koding pertanyaan terbuka, data entry, dan cleaning
b. Data analysis
c. Penulisan laporan
d. Diseminasi hasil studi di PT dan prodi
e. Publikasi jurnal/website

\section{HASIL DAN PEMBAHASAN}

\section{1) Response Rate}

Response rate pada Tracer Study STKIP Andi Matappa (TSAM) 2017 mencapai 39\%. Dalam kasus TSAM 2017, jumlah kasus tidak terkirim sebanyak 17. Ini disebabkan karena banyaknya alumni yang berdomisili di pulau terpencil yang akses komunikasi sangatlah sulit. TSAM 2017 menyasar alumni dari dua prodi yang ada di STKIP Andi Matappa yakni Pendidikan Matematika dan Bimbingan Konseling. Adapun response rate berdasarkan kedua program studi tersebut yakni $41 \%$ dan 59\% secara berturut-turut. Hasilnya dapat dilihat pada diagram berikut. 


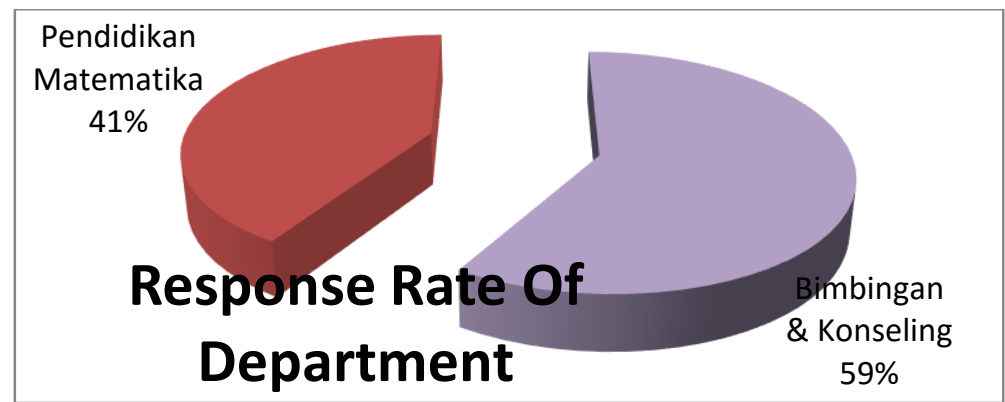

Gambar 1. Response Rate Program Studi

\section{2) Penekanan Aspek Pembelajaran}

Menurut responden TSAM 2017, penekanan aspek pembelajaran yang dinilai paling baik adalah diskusi dan demonstasi. Diskusi adalah metode pembelajaran yang paling diminati oleh lulusan prodi Bimbingan dan Konseling, sedangkan demonstrasi atau peragaan paling disukai oleh prodi pendidikan matematika. Sementara magang dan partisipasi dalam proyek dinilai paling rendah. Hal ini sejalan dengan bidang yang mereka tekuni yakni pendidikan matematika yang eksak butuh demonstrasi cara mengajar matematikasebagai calon guru sedangkan BK lebih kepada diskusi.

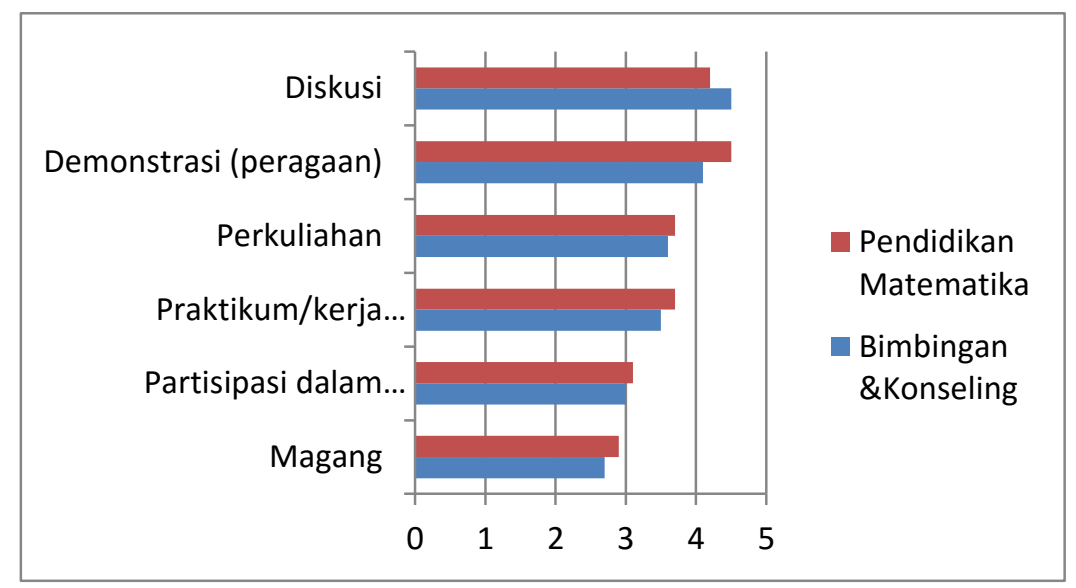

Gambar 2. Penekanan Aspek Pembelajaran

(Syafiq \& Fikawati, 2016). Pada Gambar 2

\section{3) Transisi Menuju Dunia Kerja}

Transisi menuju dunia kerja merupakan hal yang sangat penting untuk lulusan S1 karena hal itu merupakan pengalaman pertama mereka setelah periode panjang pendidikan. Masa tunggu merupakan lamanya mahasiswa mendapatkan pekerjaan setelah dinyatakan selesai menempuh studi di perguran tunggu hingga mendapatkan pekerjaan. Adapun masa tunggu yang diperoleh ada rata-rata kurang lebih 5 bulan lamanya setelah wisuda alumni STKIP Andi Matappa memproleh pekerjaan pertama mereka.

Selanjutnya variasi cara mencari pekerjaan adalah indikator penting yang mencerminkan fleksibiltas dalam memilih pekerjaa. Lebih banyak pilihan yang lebih baik dalam mencari pekerjaan akan menghasilkan hasil yang sukses menunjukkan bahwa cara mencari pekerjaan melalui bantuan relasi menjadi cara pertama dan paling banyak dipilih lulusan STKIP Andi Matappa dalam mencari pekerjaan. Hal ini disebabkan STKIP Andi Matappa yang terletak di daerah kabupaten sehingga bantuan dari relasi dan keluarga dalam memperoleh pekerjaan masih sangatlah kental. Kemudian, melalui internet menjadi cara terbanyak selanjutnya. Karena memanfaatkan teknologi internet dalam berbagai aspek lehidyupan menjadi hal yang biasa di kalangan anak muda zaman sekarang. Kecanggihan teknologi dan ditambah dengan aplikasi bursa kerja online yang banyak menjamur sekarang ini mempermudah lulusan STKIP Andi Matappa untuk mencari pekerjaan lewat jalur ini kapan saja dan di mana saja.

Cara yang paling sedikit adalah melalui 
Career Development Centre STKIP Andi Matappa. Melalui CDC karena ada beberapa alumni yang sudah menjadi Kepala Sekolah di beberapa sekolah di Kabupaten Pangkep meminta kepada pihak kampus untuk membantu mencarikan tenaga guru honorer.

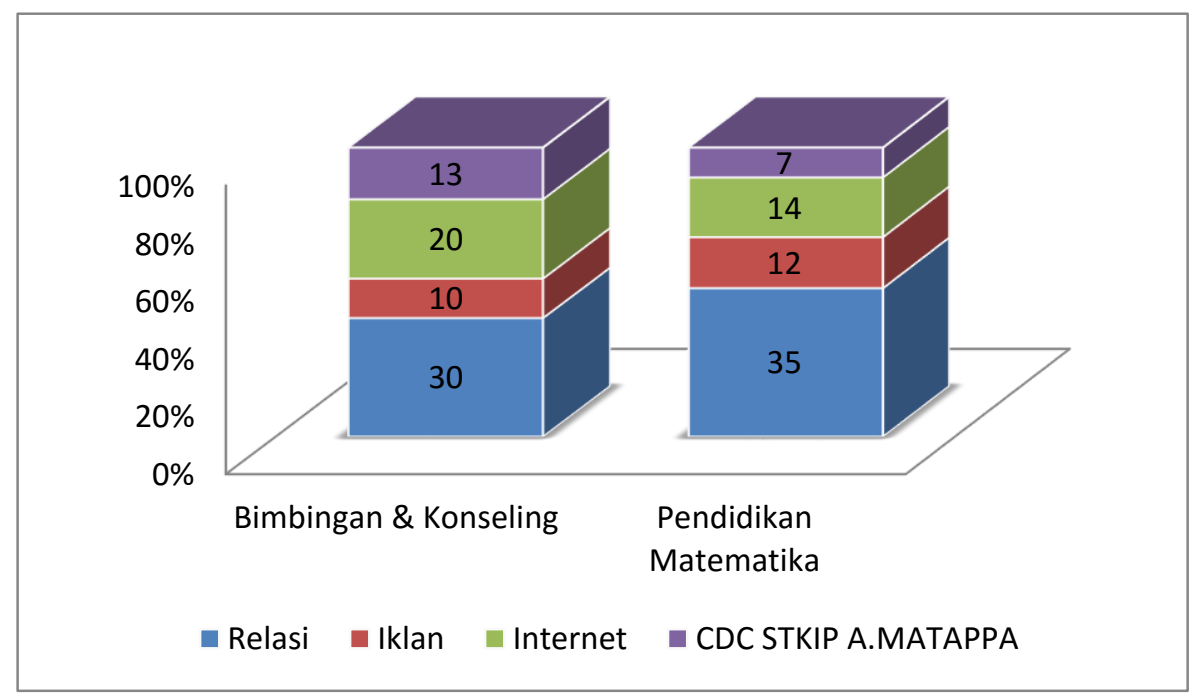

Gambar 3. Cara Lulusan Memperoleh Pekerjaan

\section{4) Situasi Pekerjaan Saat Ini}

Gambar 4 di bawah ini menunjukkan bahwa masih terdapat lulusan STKIP Andi Matappa kohort 2015 yang belum memiliki pekerjaan pada saat mengisi Tracer Study 2017.

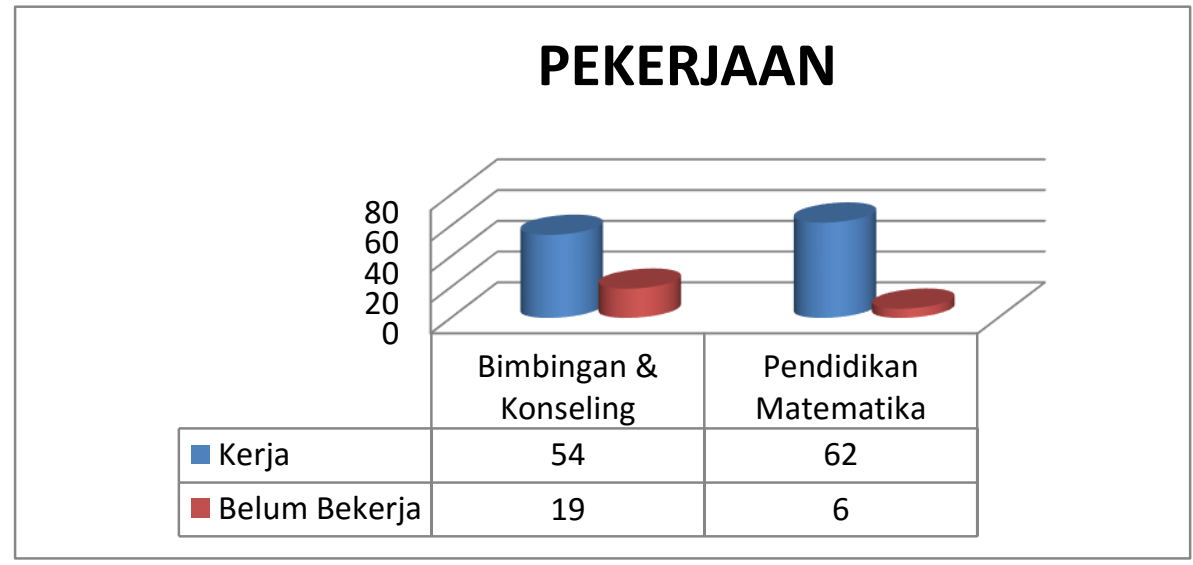

Gambar 4. Status Alumni 2015

Pada tabel berikut dapat dilihat bahwa dalam 4 minggu terakhir terhitung pada saat lulusan mengisi TSAM 2017 ada beberapa yang masih aktif mencari pekerjaan.

Tabel 1. Aktivitas Alumni Mencari Kerja

\begin{tabular}{lllll} 
No & Prodi & $\begin{array}{c}\text { Sedang mencari } \\
\text { kerja }\end{array}$ & Aktif & $\begin{array}{l}\text { Belum } \\
\text { Pasti }\end{array}$ \\
\hline 1 & Bimbingan \& Konseling & 5 & 3 & 2 \\
\hline 2 & Pendidikan Matematika & 4 & 0 & 4 \\
\hline
\end{tabular}

Selanjutnya Gambar 6 menunjukkan bahwa 43\% lulusan 2015 atau $71 \%$ responden yang mengisi kuesioner bekerja di instansi pemerintah baik itu di sekolah ataupun instansi terkait. Tidak ada satupun yang bekerja di LSM, hanya 8 orang yang bekerja di perusahaan swasta, dan 7 orang yang memilih berprofesi sebagai pengusaha atau wiraswasta. 


\begin{tabular}{|c|c|c|}
\hline 60 & \multicolumn{2}{|c|}{ TEMPAT BEKERJA } \\
\hline 40 & & \\
\hline 30 & & \\
\hline 20 & & \\
\hline 10 & & \\
\hline 0 & 1 & (- \\
\hline 0 & Bimbingan \& Konseling & Pendidikan Matematika \\
\hline - Instansi Pemerintah & 47 & 53 \\
\hline LSM & 0 & 0 \\
\hline Perusahaan Swasta & 3 & 5 \\
\hline - Wiraswasta & 3 & 4 \\
\hline Lainnya & 1 & 0 \\
\hline
\end{tabular}

Gambar 6. Jenis Tempat Bekerja Saat Ini S1 dimana alumni bekerja.

\section{5) Kompetensi yang Didapat dan Aplikasinya}

Kesenjangan antara kompetensi yang didapat saat lulus dan kompetensi yang dibutuhkan saat memasuki dunia kerja dapat dilihat pada Gambar 7. Alumni menjelaskan bahwa kompetensi alumni prodi BK an pendidikan matematika sudah sangat baik. Pada aspek kemampuan kerja yang diukur dari tanggapan alumni, alumni di sekolah merasakan bahwa tingkat integritas, profesionalisme, penggunaan TI, komunikasi, kerjasama tim, dan pengembangan diri sangat baik dan yang masih kurang adalah penguasaan bahasa asing. Hal tersebut menunjukkan bahwa alumni bimbingan konseling dan pendidikan matematika STKIP Andi Matappa dapat mengaplikasikan kompetensi yang diperoleh selama perkuliahan dan menempatkan posisi
6) Relevansi Program Studi dengan Kebutuhan Pasar Kerja

Keselarasan horizontal merupakan keselarasan antara bidang studi dengan pekerjaan alumni saat ini. Pada umumnya, keselarasan horizontal lulusan STKIP Andi Matappa Alumni dilaporkan mempunyai tingkat keselarasan yang tinggi. Alumni menjelaskan bahwa bidang studi bimbingan konseling dan pendidikan matematika sudah sangat erat kaitannya dengan pekerjaan yang sekarang tengah digeluti yakni sebagian besar berprofesi sebagai guru. Terdapat 104 orang menjawab sangat erat, kemudian terdapat 8 orang menjawab erat, 3 orang menjawab cukup erat, 1 orang menjawab kurang erta dan tidak ada yang menjawab tidak erat sama sekali.

\section{KESELARASAN HORIZONTAL}
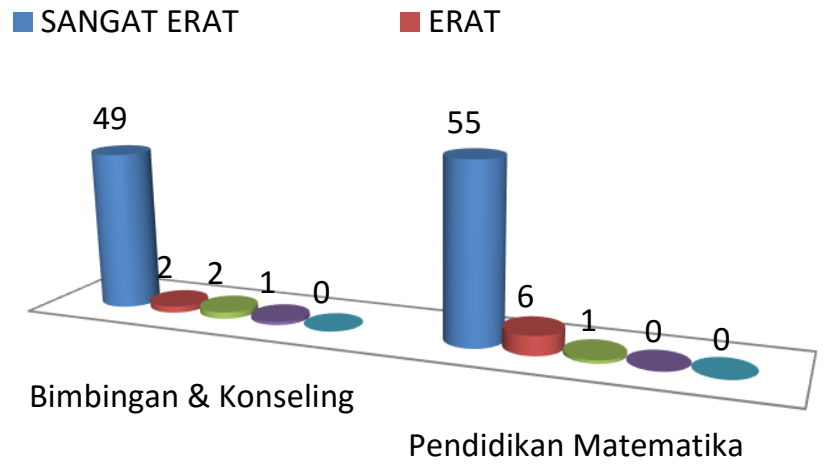

Gambar 7. Keselarasan Horizontal 
Dari gambar 7. Kesesuaian keilmuan dengan pekerjaan dapat dianalisis bahwa terdapat $89 \%$ kesesuaian alumni bekerja dengan keilmuannya, terdapat $6,9 \%$ sesuai dan 2,6\% cukup sesuai dan $0,86 \%$ kurang sesuai serta $0 \%$ memberikan respon tidak sesuai. Hal ini menbuktikan bahwa alumni prodi BK dan pendidikan matematika STKIP Andi Matappa menempati pekerjaan telah sesuai dengan keilmuan yang dimiliki.
Selanjutnya keselarasan vertikal merupakan keselarasan antara tingkat pendidikan dengan pekerjaan lulusan saat ini. Gambar 8 menunjukkan bahwa 59 orang atau $42 \%$ menjawab bahwa dibutuhkan tingkat pendidikan yang lebih tinggi, 80 orang atau $57 \%$ menjawab bahwa pekerjaan saat ini membutuhkan tingkat pendidikan yang selevel atau sama, serta 2 orang atau $1,4 \%$ menjawab tingkat yang lebih rendah.

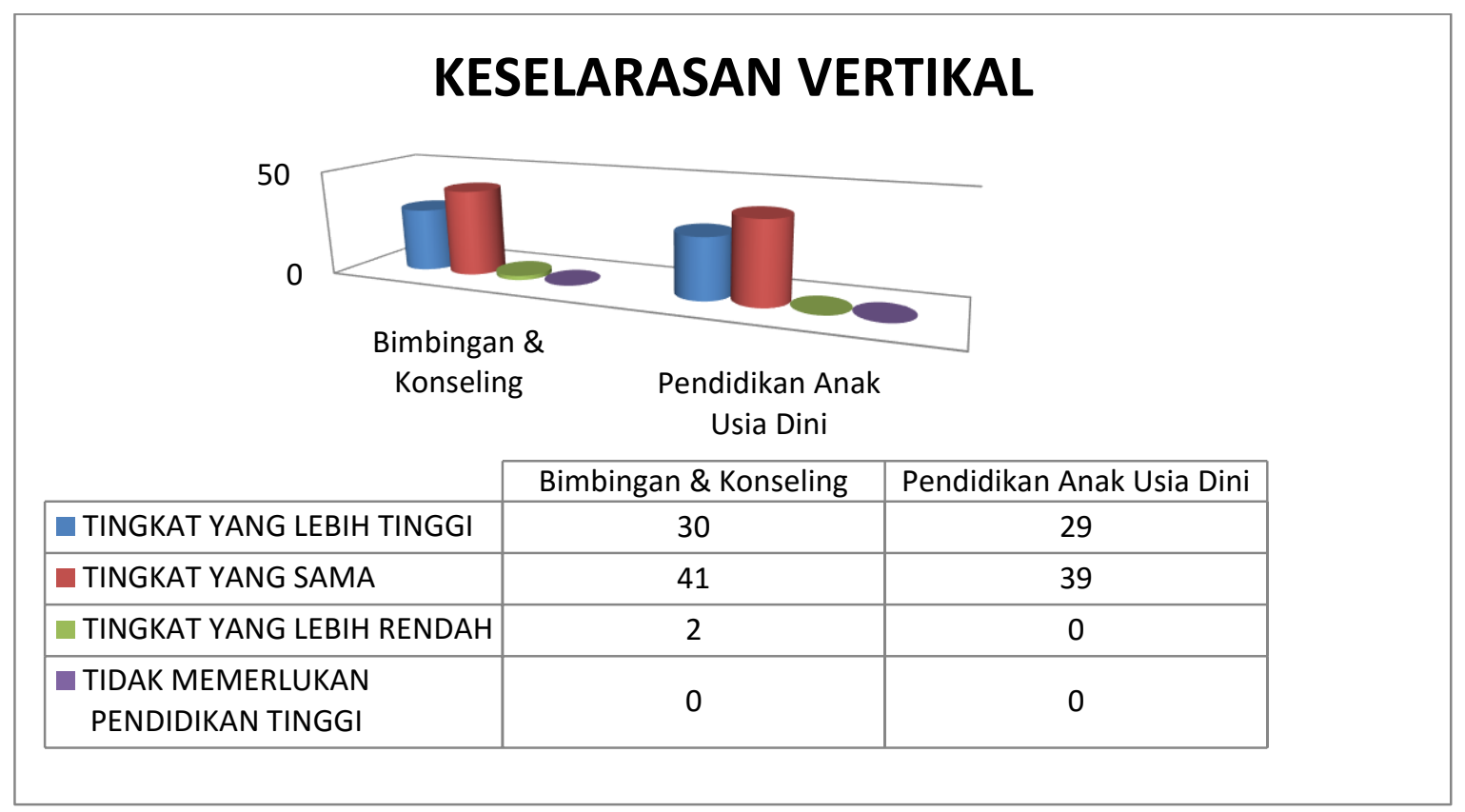

Gambar 8. Keselarasan Vertikal

\section{Pembahasan}

Peran lulusan STKIP Andi Matapa tentunya harus mampu berkiprah dalam pembangunan sesuai dengan kesesuaian pendidikannya, dapat terwujud dapat dilakukan dengan penelusuran terhadap lulusannya (Tracer Study). Hasil penelusuran alumni dapat digunakan oleh pemangku jabatan untuk mengetahui keberhasilan proses pendidikan yang telah dilakukan terhadap anak didiknya. Olehnya itu, laporan Tracer Study STKIP Andi Matappa 2017 ini adalah studi pelacakan jejak lulusan/alumni yang lulus pada tahun 2015. Hal ini bertujuan untuk mengetahui outcome pendidikan dalam bentuk transisi dari dunia pendidikan tinggi ke dunia kerja, output pendidikan yaitu penilaian diri terhadap penguasaan dan pemerolehan kompetensi, proses pendidikan berupa evaluasi proses pembelajaran dan kontribusi pendidikan tinggi terhadap pemerolehan kompetensi serta input pendidikan berupa penggalian lebih lanjut terhadap informasi sosiobiografis lulusan.
Hasil penelusuran melalui instrumen Tracer Study memberikan gambaran betapa besar peranan alumni dalam pembangunan program studi dari berbagai bidang akademik, baik dari segi pengembangan kurikulum, pembelajaran, kompetensi dan sarana dan prasaranan yang ada. Selama proses pembelajaran, pembelajaran melalui diskusi dan demonstrasi dinilai paling baik menurut alumni STKIP Andi Matappa. Hal ini tentunya karena prodi BK mengahsilkan lulusan calon konselor ddan guru BK sehinga metode diskusi sangat baik untuk menunjang karir mereka. Metode demonstrasi juga baik karena dilakukan di Ruang Microteaching, sehingga melatih lulusan prodi pendidikan matematika untuk menjadi guru yang profesional. Selanjutnya, kompetensi yang dimiliki lulusan STKIP Andi Matappa menyebabkan pencapaian pekerjaan sangat cepat. Masa tunggu mendapat pekerjaan pertama sangat cepat karena hanya menunggu paling lama sampai 5 bulan atau $88 \%$.

Dari data yang diperoleh pekerjaan yang 
paling banyak ditempati oleh alumni adalah bekerja di instansi pemerintah dalam hal ini di sekolah yakni menjadi Guru Bimbingan dan Konseling dan Guru Matematika, kemudian berkerja di swasta sebagao pegawai atau karyawan perusahaan. Namun beberapa tanggapan pengguna masih menyarankan peningaktan kompetensi kepada alumni khususnya bagi mahasiswa yang saat ini diantaranya bahasa asing atau bahasa Inggris, kecakapan atau keterampilan pengembangan diri, serta penguasaan teknologi yang lebih dikembangkan.

\section{SIMPULAN}

Berdasarkan paparan hasil Tracer Study sebagaimana di atas, dapat disimpulkan beberapa hal berikut:

1) Metode diskusi dan demonstrasi (peragaan) adalah yang paling banyak dianggap berkontribusi bagi lulusan responden.

2) Mayoritas lulusan telah bekerja sesuai bidang ilmu yang ditempuh selama masa studi, namun perlu penguatan dalam beberapa hal khususnya dalam kemampuan teknis agar lulusan dapat bekerja sesuai dengan perkembangan Ilmu Pengetahuan dan Teknologi.

\section{DAFTAR RUJUKAN}

Asmawi, M. Rosul. Strategi Meningkatan Mutu Lulusan Perguruan Tinggi.

Jurnal MAKARA, SOSIAL HUMANIORA, VOL. 9, NO. 2, DESEMBER 2005

Bakhtiar, M.I. 2014. Laporan Survey Pelacakan Alumni Dalam Rangka Pengembangan Prodi Bimbingan Konseling. Pangkep: STKIP Andi Matappa.

Bakhtiar, M.I \& Latif,S. (2017) Tracer Study Alumni : Upaya Pengembangan Prodi Bimbingan Konseling Universitas Negeri Makassar. Jurnal Kajian Bimbingan dan Konseling , 2 (1)

Panduan Program Bantuan Pengembangan Layanan Pusat Karir Lanjutan (BPLPKL) 2017. Ditjen Pembelajaran dan Kemahasiswaan Kementerian Riset, Teknologi dan Pendidikan Tinggi
Syafiq, A dan Fikawati,S. 2016. Metodologi dan Manajemen Tracer Study. Depok: PT Rajagrafindo Persada. 